\title{
Effect of Sleep Disorder on Delirium in Post-Cardiac Surgery Patients
}

\author{
Hongbai Wang, Liang Zhang, Qipeng Luo, Yinan Li, Fuxia Yan
}

\begin{abstract}
Background: Post-cardiac surgery patients exhibit a higher incidence of postoperative delirium (PD) compared to non-cardiac surgery patients. Patients with various cardiac diseases suffer from preoperative sleep disorder (SPD) induced by anxiety, depression, breathing disorder, or other factors. Objective: To examine the effect of sleep disorder on delirium in post-cardiac surgery patients. Methods: We prospectively selected 186 patients undergoing selective cardiac valve surgery. Preoperative sleep quality and cognitive function of all eligible participants were assessed through the Pittsburgh Sleep Quality Index (PSQI) and the Montreal Cognitive Assessment, respectively. The Confusion Assessment Method for Intensive Care Unit was used to assess PD from the first to seventh day postoperatively. Patients were divided into two groups according to the PD diagnosis: (1) No PD group and (2) the PD group. Results: Of 186 eligible patients, $29(15.6 \%)$ were diagnosed with PD. A univariate analysis showed that gender $(p=0.040)$, age $(p=0.009)$, SPD $(p=0.008)$, intraoperative infusion volume $(p=0.034)$, postoperative intubation time $(p=0.001)$, and intensive care unit stay time $(p=0.009)$ were associated with PD. A multivariate logistic regression analysis demonstrated that age (odds ratio (OR): $1.106 ; p=0.001)$ and SPD (OR: 3.223; $p=0.047)$ were independently associated with PD. A receiver operating characteristic curve demonstrated that preoperative PSQI was predictive of PD (area under curve: 0.706; 95\% confidence interval: 0.595-0.816). A binomial logistic regression analysis showed that there was a significant association between preoperative 6 and 21 PSQI scores and PD incidence $(p=0.009)$. Conclusions: Preoperative SPD was significantly associated with PD and a main predictor of PD.
\end{abstract}

RÉSUMÉ : Les effets des troubles du sommeil sur les manifestations de delirium de patients ayant subi une chirurgie cardiaque. Contexte : Les patients qui se remettent d'une chirurgie cardiaque tendent à présenter une incidence plus élevée de delirium postopératoire (DPO) si on les compare à d'autres patients dont la chirurgie ne concernait pas le cœur. Il faut aussi ajouter que les patients aux prises avec diverses maladies cardiaques tendent par ailleurs à être atteints de troubles du sommeil préopératoires (TSPO). Objectif : Examiner les effets des TSPO sur le DPO de patients qui se remettent d'une intervention chirurgicale du cœur. Méthodes: Nous avons sélectionné de façon prospective 186 patients ayant subi une intervention sélective des valves cardiaques. Tant la qualité du sommeil des patients admissibles à cette étude que leur fonction cognitive, et ce, avant leur intervention, ont été évaluées respectivement selon le Pittsburgh Sleep Quality Index (PSQI) et l'Évaluation cognitive de Montréal (« MoCA » en anglais). On a aussi utilisé la Confusion Assessment Method (CAM) pour les soins intensifs afin d'évaluer le DPO du premier au septième jour suivant l'intervention chirurgicale. Pour les fins de cette étude, nous avons divisé nos patients en deux groupes selon le diagnostic de DPO posé : (1) aucune manifestation de DPO et (2) manifestations de DPO. Résultats : Sur 186 patients admissibles, $29(15,6 \%)$ ont reçu un diagnostic de DPO. Une analyse univariée a montré que des variables telles que le sexe $(p=0,040)$, l'âge $(p=0,009)$, des signes de TSPO $(p=0,008)$, le volume de perfusion peropératoire $(p=0,034)$, le temps d'intubation postopératoire $(p=0,001)$ ainsi que la durée de séjour aux soins intensifs $(p=0,009)$ pouvaient être associées au DPO. D'un autre côté, une analyse de régression logistique multivariée a démontré que l'âge ( $\mathrm{RC}: 1,106 ; p=0,001)$ et des signes de TSPO (RC :3,223; $p=0,047)$ pouvaient être indépendamment associés à des manifestations de DPO. Enfin, une courbe dite « ROC » (receiver operating characteristic) a démontré que les scores préopératoires au PSQI avaient une valeur prédictive en ce qui regarde le DPO (ASC : 0,706 ; IC $95 \%$ : 0,595 - 0,816). De fait, une régression logistique binominale a révélé qu'il y avait une association notable entre des scores de 6-21 au PSQI et l'incidence de DPO $(p=0,009)$. Conclusions : En somme, nous avons trouvé que les TSPO, en plus d'être associés de manière significative au DPO, constituent un important prédicteur de ce syndrome confusionnel.

Keywords: Sleep disorder, Pittsburgh Sleep Quality Index, Confusion assessment method for intensive care unit, Postoperative delirium doi:10.1017/cjn.2020.62

Can J Neurol Sci. 2020; 47: 627-633

\section{INTRODUCTION}

Postoperative delirium (PD) is a state of acute and fluctuating brain dysfunction, manifested by inattention, disorganised thinking and altered states of consciousness, ${ }^{1}$ which can commonly occur during the 3 days after surgery. ${ }^{2}$ In previous studies, relative to patients undergoing non-cardiac surgeries, post-cardiac surgery patients demonstrated a much higher incidence of delirium, of $5 \%-72 \%{ }^{3,4}$ Delirium can significantly increase the incidence of adverse events and even the chance of a 30-day death after surgery. ${ }^{5-7}$

From the Department of Anesthesiology, Fuwai Hospital, Chinese Academy of Medical Sciences and Peking Union Medical College, Beijing, China (HW, LZ, QL, YL, FY)

Received November 12, 2019. Final Revisions Submitted February 5, 2020. Date of Acceptance March 21, 2020.

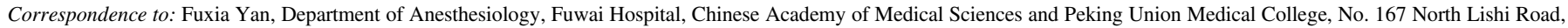

Xicheng District, Beijing, China. Email: yanfuxia@sina.com 
Sleep disorder (SPD) is a common issue among adults given their accelerated social rhythm, frequent change of life style, and factors that have close relationships with psychological illness. ${ }^{8,9}$ Some studies have found that both preoperative obstructive sleep apnoea (OSA) through sleep-disordered breathing and postoperative poor sleep quality exhibit significant correlations with PD. ${ }^{10-13}$ Additionally, patients with cardiac disease display higher incidence of SPD due to frequent cardiac pain and discomfort, as well as long-term psychological pressure. ${ }^{14-16}$ However, no previous systematic prospective studies have evaluated the effect of preoperative chronic SPD on PD for patients following cardiac surgery.

\section{Methods}

This article describes a prospective observational cohort study. The Ethics Committee of the Chinese Academy of Medical Sciences Fuwai Hospital in Beijing approved this study, and all patients provided written informed consent. The inclusion criteria included (1) age $\geq 18$ years and (2) the patient undergoing valve surgery on pump. The exclusion criteria included (1) having a history of delirium or dementia; (2) having a history of brain surgery, cerebral haemorrhage or infarction; (3) having preoperative myasthenia gravis; (4) having grade IV cardiac function (New York Heart Association); (5) having death chances expected within 48 hours after surgery; (6) going through another surgery within seven postoperative days; (7) having serious preoperative liver (Child-Pugh grading C) and renal (stage 3-4 according to Chronic Kidney Disease grading) dysfunction and (8) being unable to communicate due to hearing and/or language issues.

All patients underwent open heart cardiac valve surgery on pump under general anaesthesia of the same anaesthesia programme. General anaesthesia intravenous medications included midazolam, sufentanil, etomidate, and cisatracurium. Anaesthetics sustaining anaesthesia included: propofol, sufentanil, dexmedetomidine, cisatracurium and sevoflurane. A Bispectral Index (BIS) was used to monitor the depth of anaesthesia having maintained BIS values between 40 and 60 during surgery. A normal body temperature was maintained except for light hypothermia (nasopharyngeal temperature: $30-34^{\circ} \mathrm{C}$ ) during aortic clamping. Anticholinergics were prohibited perioperatively due to the possible occurrence of latent mental disorder.

The Pittsburgh Sleep Quality Index (PSQI) has proven to be an effective method to assess sleep quality. It includes 18 items in seven parts, and its score ranges from 0 to 21 (Supplementary file 1). A score of five in the PSQI is regarded as a cutoff point of SPD for adults. The higher the PSQI score is, the more serious the SPD is. ${ }^{17}$ The sleep quality of participants throughout a month before hospital admission was assessed through the PSQI.

We evaluated the preoperative cognitive state of participants through the Montreal Cognitive Assessment (MoCA) which has been found to have higher sensitivity than the Mini-Mental State Examination. ${ }^{18}$ The total score of the MoCA is 30. An individual is said to have cognitive dysfunction if the score is less than $21 .^{18}$

The Confusion Assessment Method for Intensive Care Unit (CAM-ICU) is widely used to assess delirium. CAM-ICU is subdivided into four parts: (1) acute change of mental status and behaviour during the past 24 hours; (2) inattention; (3) disordered thinking and (4) altered state of consciousness (Supplementary file 2). The diagnosis of delirium is made when items (1), (2) and
(3) or (4) are met. ${ }^{19}$ However, before the mental status of a patient was assessed, their sedation level was evaluated by the Richmond Agitation-Sedation Scale (RASS) first (Supplementary file 3). Only when the RASS score was -3 or more was the assessment of delirium processed through CAM-ICU. ${ }^{20}$ Additionally, delirium can be divided into three types according to RASS scores: (1) hypoactive type: when the RASS score is less than 0; (2) hyperactive type: when the RASS score is more than 0 and (3) mixed: hypoactive and hyperactive types alternately occuring. ${ }^{21}$ The delirium was assessed only once in the first 24 hours, and the time of assessment was as close as possible to 24 hours of the end of the surgery to minimise the impact of anaesthetics on the consciousness of patients. From the second to the seventh day postoperatively, delirium was assessed twice daily (8:00-10:00 and 18:00-20:00). ${ }^{22,23}$

All participants received a perfect analgesia score (Rest Numerical Rating Scale < 4) after surgery through intravenous sufentanil, dezocine and/or acetaminophen. When needed, propofol and/or midazolam were used to sedate patients. Dexmedetomidine and/or haloperidol were injected to control delirium episodes.

The variables included gender, age, body mass index, educational level, alcohol abuse history, smoking, preoperative PSQI score, preoperative MoCA score, anaesthesia duration, surgery, cardiopulmonary bypass, aortic clamping and hypothermia, post-surgery intubation time, ICU stay, the number of patients receiving sedatives and opioid analgesics postoperatively and number of patients diagnosed with PD. We divided all participants into two groups according to the diagnosis of PD: (1) the no PD (NPD) group and (2) the PD group.

\section{Statistical Analysis}

SPSS 22.0 (IBM Corp., Armonk, NY, USA) was used to analyse the data. The normality of the continuous variable distribution was determined through the Kolmogorov-Smirnov test. Continuous variables of normal distribution were presented as mean \pm standard deviation and the data of abnormal distribution as median, interquartile range and range. Categorical variables were expressed as percentages. Continuous variables were analysed through Student's $t$-test and Mann-Whitney $U$-test, and categorical variables through Pearson's chi-square test. A multivariate logistic regression model was used to analyse the correlation of PD and covariates that were found to be associated with delirium in the univariate analysis. An area under curve (AUC) was generated from the receiver operating characteristic (ROC) curve to display the diagnostic accuracy of preoperative PSQI score on PD. We used a binomial logistic regression to analyse the association between preoperative sleep quality and PD based on PSQI values (two groups: 0-5 and 6-21). Significance was marked by a $p$ value of less than 0.05 .

\section{Sample Size Calculation}

The incidence of PD was about $50 \%$ for patients with poor sleep quality according to previous studies. ${ }^{24}$ A decrease of nearly $40 \%$ in incidence of PD occurred when patient sleep quality improved. $^{25}$ The odds ratio (OR) was of about 5.24 for the risk of PD in patients with $\mathrm{SPD},{ }^{26}$ and the proportion of patients in the SPD group and those in the no SPD group was 


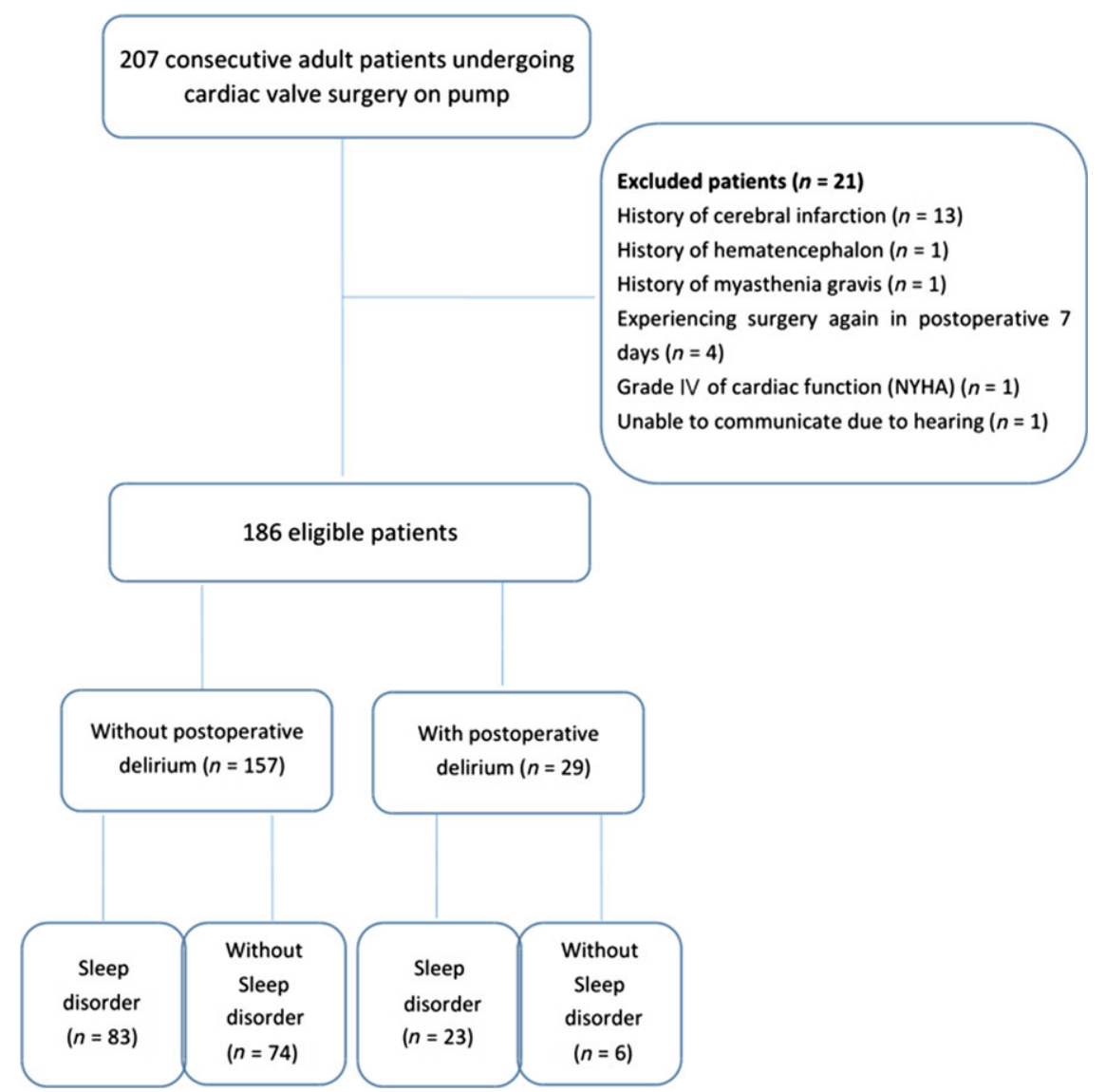

Figure 1: The flow chart of screening cases for this prospective study. NYHA = New York Heart Association.

1:1. The minimum sample size of 65 patients in the SPD group was detected when choosing a power of $90 \%$ and a two-sided $\alpha$ of 0.05 . Finally, we found that the total minimum sample size of 130 was required.

\section{Results}

From May 22 to July 29, 2019, 207 adult patients undergoing cardiac valve surgery on pump were consecutively included, 21 of these were excluded based on the exclusion criteria. The 186 eligible patients (SPD: 106 participants; no SPD: 80 participants) were divided into two groups according to PD: (1) NPD: $n=157$ (84.4\%) and (2) PD: $n=29$ (15.6\%). From the total of $157,83(52.9 \%)$ patients without PD had preoperative SPD, and $23(79.3 \%)$ of 29 patients with PD suffered from preoperative chronic SPD. No patient died or withdrew during the follow-up period (Figure 1).

The univariate analysis of the baseline values and general characteristics of participants is shown in Table 1. Risk factors associated with PD were male $(p=0.040)$, age $(p=0.009)$, preoperative SPD $(p=0.008)$, intraoperative infusion volume $(p=0.034)$, postoperative intubation time $(p=0.001)$ and ICU stay $(p=0.009)$.

The multivariate logistic regression analysis of age, intraoperative infusion volume, postoperative intubation time and ICU stay as continuous variables and male gender and preoperative SPD as categorical variables showed that age (OR: 1.106; 95\% confidence interval $(\mathrm{CI}): 1.043-1.173 ; p=0.001)$ and preoperative SPD (OR: 3.223; 95\% CI: 1.017-10.211; $p=0.047$ ) were significantly associated with PD after adjustment for covariates (Table 2).

A binomial logistic regression analysis performed to assess the relationship between preoperative PSQI scores and PD found no significant association among patients with preoperative $0-5$ scores (OR: 1.106; 95\% CI: 0.595-2.059; $p=0.749$ ), but a significant association was found for patients with 6-21 scores (OR: 0.828; 95\% CI: 0.720-0.953; $p=0.009$ ) (Table 3). The ROC curve showed that the preoperative PSQI score had a certain predictive value for PD (AUC: 0.706; 95\% CI: 0.595-0.816) (Figure 2).

\section{Discussion}

We assessed preoperative sleep quality and PD of all participants through the method of questionnaire surveys. The researchers who performed PD assessment were unaware of the patients' sleep quality before surgery. Dexmedetomidine is regarded as an effective drug to prevent PD attack due to its functions of antianxiety, improvement of sleep quality, and analgesia. ${ }^{27-29}$ All enrolled patients in this study received routine dexmedetomidine infusion during surgery; meanwhile, dexmedetomidine was prohibited after surgery except for delirium occurrence. Therefore, all participants in this study had the same baseline for dexmedetomidine administration. This study demonstrated that 


\section{Table 1: Univariate analysis according to postoperative diagnosis of delirium}

\begin{tabular}{|c|c|c|c|c|}
\hline & $\begin{array}{l}\text { All patients } \\
(n=186)\end{array}$ & $\begin{array}{c}\text { NPD } \\
(n=157)\end{array}$ & PD $(n=29)$ & $p$ \\
\hline Male $(n(\%))$ & $105(56.5)$ & 94 (59.9) & 11(37.9) & 0.040 \\
\hline $\begin{array}{l}\text { Body mass index }\left(\mathrm{kg} / \mathrm{m}^{2}\right) \\
(\text { mean } \pm \mathrm{SD})\end{array}$ & $24.7 \pm 3.5$ & $24.6 \pm 3.5$ & $24.6 \pm 3.7$ & 0.952 \\
\hline Age (year) $($ mean \pm SD) & $53.6 \pm 11.9$ & $56.2 \pm 11.2$ & $63.0 \pm 8.1$ & 0.009 \\
\hline Educational level (year) & $10.2 \pm 4.7$ & $8.9 \pm 4.2$ & $9.3 \pm 4.4$ & 0.669 \\
\hline Alcohol abuse $(n(\%))^{\mathrm{a}}$ & $8(4)$ & $6(4)$ & $2(7)$ & 0.613 \\
\hline Smoking $(n(\%))^{\mathrm{b}}$ & 29 (15.6) & $25(15.9)$ & $4(13.8)$ & 1.000 \\
\hline $\begin{array}{l}\text { Preoperative cognitive } \\
\text { dysfunction }(n(\%))\end{array}$ & $31(16.7)$ & $23(14.6)$ & $8(27.6)$ & 0.086 \\
\hline $\begin{array}{l}\text { Preoperative sleep } \\
\text { disorder }(n(\%))\end{array}$ & $106(57)$ & $83(52.9)$ & $23(79.3)$ & 0.008 \\
\hline $\begin{array}{l}\text { Duration of anaesthesia } \\
\text { (minutes) (mean } \pm \mathrm{SD})\end{array}$ & $271.0 \pm 61.7$ & $268.4 \pm 49.2$ & $290.6 \pm 14.8$ & 0.167 \\
\hline $\begin{array}{l}\text { Duration of surgery } \\
\text { (minutes) }(\text { mean } \pm \mathrm{SD})\end{array}$ & $227.7 \pm 59.2$ & $225.0 \pm 48.3$ & $247.9 \pm 76.5$ & 0.147 \\
\hline $\begin{array}{l}\text { Duration of } \\
\text { cardiopulmonary bypass } \\
\text { (minutes) (mean } \pm \mathrm{SD})\end{array}$ & $113.3 \pm 40.3$ & $113.6 \pm 38.9$ & $112.8 \pm 47.0$ & 0.937 \\
\hline $\begin{array}{l}\text { Duration of aortic } \\
\text { clamping (minutes) } \\
\text { (mean } \pm \text { SD) }\end{array}$ & $82.7 \pm 30.4$ & $86.3 \pm 36.1$ & $81.0 \pm 28.9$ & 0.518 \\
\hline $\begin{array}{l}\begin{array}{l}\text { Duration of hypothermia } \\
\text { (minutes) }(\text { mean } \pm \mathrm{SD})\end{array}\end{array}$ & $66.8 \pm 27.0$ & $70.8 \pm 28.9$ & $63.4 \pm 24.3$ & 0.332 \\
\hline $\begin{array}{l}\text { Blood loss during surgery } \\
(\mathrm{ml})(\text { mean } \pm \mathrm{SD})\end{array}$ & $603.2 \pm 61.3$ & $582.1 \pm 78.7$ & $611.4 \pm 74.5$ & 0.161 \\
\hline $\begin{array}{l}\text { Intraoperative infusion } \\
\text { volume }(\mathrm{ml}) \\
(\text { mean } \pm \mathrm{SD})\end{array}$ & $643.8 \pm 369.6$ & $600.0 \pm 243.5$ & $843.1 \pm 541.4$ & 0.034 \\
\hline \multicolumn{5}{|l|}{$\begin{array}{l}\text { Number of postoperative } \\
\text { sedative and/or opioid } \\
\text { analgesics administration } \\
(n(\%))\end{array}$} \\
\hline Propofol & $172(92.5)$ & $146(93)$ & $26(89.7)$ & 0.461 \\
\hline Midazolam & 85 (45.7) & $70(44.6)$ & $15(51.7)$ & 0.545 \\
\hline Sufentanil & $186(100)$ & $157(100)$ & $29(100)$ & 1.000 \\
\hline Dezocine & $110(59.1)$ & $93(59.2)$ & 17 (58.6) & 1.000 \\
\hline $\begin{array}{l}\text { Postoperative intubation } \\
\text { time (minutes) } \\
(\text { mean } \pm \text { SD) }\end{array}$ & $957.5 \pm 556.7$ & $807.2 \pm 220.0$ & $1384.8 \pm 804.7$ & 0.001 \\
\hline Time of ICU stay (day) & $2.4 \pm 1.7$ & $2.2 \pm 0.3$ & $3.6 \pm 0.5$ & 0.009 \\
\hline
\end{tabular}

$\mathrm{SD}=$ standard deviation.

aAlcohol abuse was defined as alcohol intake more than twice daily.

${ }^{\mathrm{b}}$ Smoking was defined as current smoking or smoking cessation of less than 6 month.

long-term preoperative SPD was an important risk factor associated with PD for post-cardiac valve surgery. Furthermore, the PSQI was predictive of PD, especially for patients with PSQI scores higher than 6.

PD is a common complication for patients following cardiac $^{30,31}$ and major non-cardiac surgeries. ${ }^{32}$ Previous studies
Table 2: Logistic regression for PD as an independent variable

\begin{tabular}{l|c|c|c|c|c|c}
\hline & $\begin{array}{c}\text { Regression } \\
\text { coefficient } \boldsymbol{B}\end{array}$ & $\begin{array}{c}\text { Standard } \\
\text { error }\end{array}$ & Wald & $\boldsymbol{p}$ & OR & $\begin{array}{c}\mathbf{9 5 \%} \text { CI for } \\
\text { OR }\end{array}$ \\
\hline Male & -0.226 & 0.496 & 0.207 & 0.649 & 0.798 & $0.302-2.108$ \\
\hline Age & 0.101 & 0.030 & 11.324 & 0.001 & 1.106 & $1.043-1.173$ \\
\hline Sleep disorder & 1.170 & 0.588 & 3.955 & 0.047 & 3.223 & $1.017-10.211$ \\
\hline $\begin{array}{l}\text { Intraoperative } \\
\text { infusion } \\
\text { volume }\end{array}$ & 0.001 & 0.001 & 2.799 & 0.094 & 1.001 & $1.000-1.002$ \\
\hline $\begin{array}{l}\text { Postoperative } \\
\text { intubation } \\
\text { time }\end{array}$ & 0.001 & 0.000 & 1.724 & 0.189 & 1.001 & $1.000-1.001$ \\
\hline $\begin{array}{l}\text { Time of ICU } \\
\text { stay }\end{array}$ & 0.235 & 0.149 & 2.487 & 0.115 & 1.265 & $0.945-1.695$ \\
\hline
\end{tabular}

Table 3: Binomial logistic regression analysis to inform the relationship of preoperative sleep quality and PD based on the PSQI scores

\begin{tabular}{l|c|c|c}
\hline PSQI score & OR & 95\% CI for OR & $\boldsymbol{p}$ \\
\hline $0-5$ & 1.106 & $0.595-2.059$ & 0.749 \\
\hline $6-21$ & 0.828 & $0.720-0.953$ & 0.009 \\
\hline
\end{tabular}

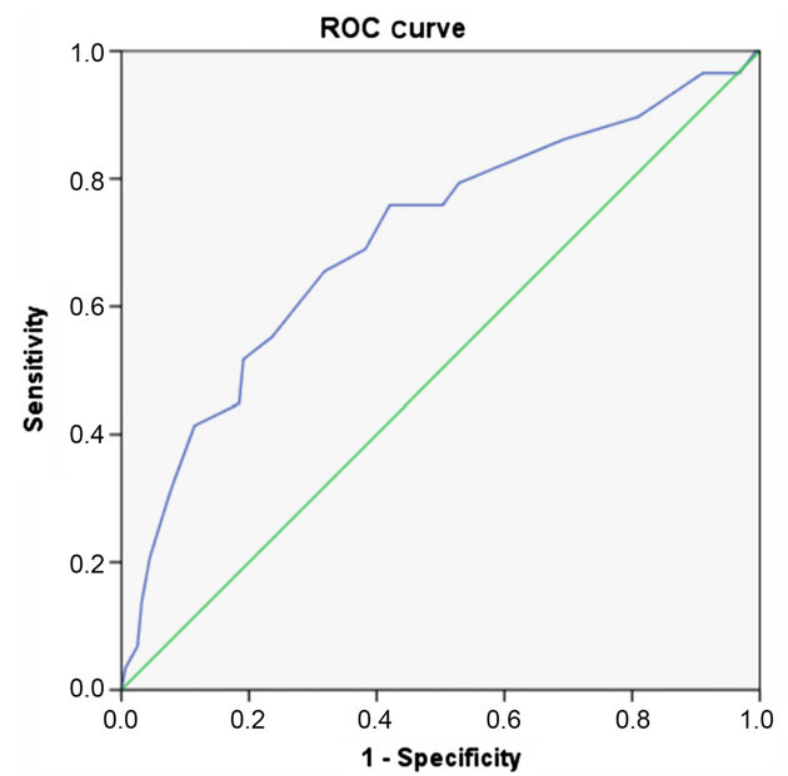

Figure 2: ROC curve of preoperative PSQI score of predictability for postoperative delirium. The AUC was 0.706 .

determined several risk factors associated with PD, including advanced age, low education level, preoperative cognitive dysfunction, smoking, cardiac or macrovascular surgery, major non-cardiac surgeries, perioperative use of sedative and analgesic drugs, postoperative imperfect analgesia, among others. ${ }^{33-35}$ Preoperative or postoperative OSA has also been regarded as 
a risk factor of PD based on previous clinical studies. ${ }^{10,36,37}$ However, no previous studies have reported the effect of preoperative long-term insomnia induced by anxiety, depression, non-psychotic, and non-OSA factors on PD. The PSQI exhibits a sensitivity of $89.6 \%$ and a specificity of $86.5 \%$ in distinguishing good and poor sleep quality; ${ }^{17}$ it can analyse SPD induced by anxiety, depression, breathing disorders, and other factors, being able to describe sleep conditions comprehensively and in detail. ${ }^{17}$

SPD can provoke cognitive and behavioural dysfunctions. Chronic insomnia induced by anxiety and depression is associated with memory impairment, dementia and inattention, including impaired alerting behaviour, orienting and executive control. ${ }^{38-40}$ Similarly, OSA-related chronic intermittent hypoxia and hypercapnia can also hinder attention, memory and cognition. ${ }^{41,42}$ Specifically, how SPD generates cognitive and behavioural dysfunction is still unclear. A large number of cortisol production induced by hypothalamic-pituitary-adrenal axis hyperactivity may be a possible mechanism that explains how SPD influences cognitive and behavioural dysfunction. Studies have reported a potential mechanism in which cortisol is transferred to the central nervous system leading to apoptosis of neurons in hippocampal area through activating brain-derived neurotrophic growth factortropomyosin-related kinase B signalling pathway. ${ }^{43-46}$ Longterm OSA-related hypoxia and hypercapnia can impair vascular endothelial cells and enhance sensitivity of the vasoconstrictive response to vasoconstrictive mediators. It can also produce inflammation and oxidative stress response leading to an hypercoagulative state, increasing the risk of vascular dementia. ${ }^{47,48}$ Moreover, neuronal apoptosis induced by SPD, related to autonomic nervous system imbalance, may also constitute pathogenic factors of cognitive and behavioural dysfunction. ${ }^{49}$ In addition, preoperative cognitive dysfunction is closely associated with PD. ${ }^{50}$ Therefore, the relevance of studying the impact of preoperative sleep quality on PD for post-cardiac surgery patients is clear.

In the current study, we found six possible risk factors associated with PD through the univariate analysis, including gender (male), age, preoperative SPD, intraoperative infusion volume, postoperative intubation time and ICU stay. However, none were determined because of their interaction of each other. Hence, we adjusted covariates through a multivariate logistic regression model, which showed age and preoperative SPD as reliable independent risk factors. AUC generated from the ROC curve can predict the diagnostic value of a risk factor to the outcome. An AUC of over 0.70 means that a given risk factor has a certain accuracy in predicting outcome. ${ }^{51}$ We performed the ROC curve to observe the effect of preoperative PSQI scores on incidence of PD and obtained an AUC of 0.706 and found that preoperative PSQI score is a predictor of PD. Furthermore, the analysis of PSQI scores showed that there was no significant association between scores and PD among patients with scores $0-5$, but a significant association was displayed for patients with 6-21 scores. These results hinted that the diagnostic value of PSQI scores in PD is mainly reflected in patients with sleep disorders.

Our study has some advantages in demonstrating preoperative SPD is associated with PD. First, patients were undergoing selective cardiac valve surgery to decrease confounding factors produced by different surgical types. Second, the programme of general anaesthesia was standardised to decrease the possibility of a narcotic administration bias. Third, patients were required to be over the age of 18 , so this can explain the effect of preoperative SPD on PD in adults of all ages, not just in older adults. Fourth, the comprehensive evaluation of sleep problems through the PSQI included insomnia induced by anxiety, depression, non-psychotic factors and sleep disturbance breathing produced by OSA. Fifth, the author's institute is a word-class centre for cardiac and macrovascular diseases, and advanced valve surgeries techniques were applied to decrease the bias caused by different surgical methods.

On the other hands, there are limitations in this study. First, we may have missed delirium occurrence at the follow-up time, implying a higher incidence of PD possibly occurs, and we are unsure of how a higher incidence of PD could influence the outcome. Second, PSQI and CAM-ICU are both self-report questionnaires for sleep quality and delirium, and therefore, some bias in the diagnoses of SPD and delirium was inevitable. Third, we did not find any cases of delirium occurring in those younger than 40 years; thereby, a large-scale questionnaire investigation including more patients should be performed to further verify the association of preoperative SPD and PD, even though the number of participants in this study is over the required minimum sample size.

\section{Conclusions}

This study demonstrated that preoperative SPD is an independent risk factor leading to PD for patients following cardiac valve surgery. Furthermore, it was found that preoperative PSQI scores have a predictive value for occurrences of PD. This study, therefore, provides evidence that preoperative sleep quality improvement might become an effective method to decrease the incidence of PD. It is noteworthy to add that special attention from anaesthetists, surgeons and doctors in the ICU is necessary for patients with preoperative SPD, in order to take effective preventive measures to avoid the occurrence of delirium.

\section{ACKNOWLEDGMENTS}

We are grateful to Professor Wang Yang from the Departments of Statistics for supervising the statistical analysis and other experts who provided valuable suggestions for our work.

\section{Disclosures}

The authors have no conflicts of interest to declare.

\section{STATEMENT of Authorship}

HW contributed to study design, screening of patients, data collection and drafting of the manuscript. LZ performed the preoperative sleep quality and cognition assessment. YL was responsible for PD assessment. QL collected data and carried out the statistical analysis. FY supervised the entire test process and guaranteed the accuracy of the data.

\section{REFERENCES}

1. Lipowski ZJ. Delirium (acute confusional states). JAMA.1987; 258:1789-92.

2. Munk L, Andersen G, Møller AM. Post-anaesthetic emergence delirium in adults: incidence, predictors and consequences. Acta Anaesthesiol Scand. 2016;60:1059-66. 
3. Sockalingam S, Parekh N, Bogoch II, et al. Delirium in the postoperative cardiac patient: a review. J Card Surg. 2005;20: 560-67.

4. Koster S, Oosterveld FG, Hensens AG, Wijma A, van der Palen J. Delirium after cardiac surgery and predictive validity of a risk checklist. Ann Thorac Surg. 2008;86:1883-7.

5. Koster S, Hensens AG, van der Palen J. The long-term cognitive and functional outcomes of postoperative delirium after cardiac surgery. Ann Thorac Surg. 2009;87:1469-74.

6. Mangusan RF, Hooper V, Denslow SA, Travis L. Outcomes associated with postoperative delirium after cardiac surgery. Am J Crit Care. 2015;24:156-63.

7. Krzych LJ, Wybraniec MT, Krupka-Matuszczyk I, et al. Detailed insight into the impact of postoperative neuropsychiatric complications on mortality in a cohort of cardiac surgery subjects: a 23,000-patient-year analysis. J Cardiothorac Vasc Anesth. 2014; 28:448-57.

8. Olini N, Rothfuchs I, Azzinnari D, Pryce CR, Kurth S, Huber R. Chronic social stress leads to altered sleep homeostasis in mice. Behav Brain Res. 2017;327:167-73.

9. Williams NJ, Grandner MA, Wallace DM, et al. Social and behavioral predictors of insufficient sleep among African Americans and Caucasians. Sleep Med. 2016;18:103-7.

10. Roggenbach J, Klamann M, von Haken R, Bruckner T, Karck M, Hofer S. Sleep-disordered breathing is a risk factor for delirium after cardiac surgery: a prospective cohort study. Crit Care. 2014; 18:477.

11. Leung JM, Sands LP, Newman S, et al. Preoperative sleep disruption and postoperative delirium. J Clin Sleep Med. 2015;11:907-13.

12. Lindroth $\mathrm{H}$, Bratzke L, Twadell S, et al. Predicting postoperative delirium severity in older adults: the role of surgical risk and executive function. Int J Geriatr Psychiatry. 2019;34:1018-1028.

13. Chung F, Liao P, Yang Y, et al. Postoperative sleep-disordered breathing in patients without preoperative sleep apnea. Anesth Analg. 2015;120:1214-24.

14. Yatsu S, Kasai T, Suda S, et al. Prevalence and significance of restless legs syndrome in patients with coronary artery disease. Am J Cardiol. 2019;123:1580-6.

15. Balcan B, Thunström E, Strollo Jr., PJ, Peker Y. Determinants of depressive mood in coronary artery disease patients with obstructive sleep apnea and response to continuous positive airway pressure treatment in non-sleepy and sleepy phenotypes in the RICCADSA cohort. J Sleep Res. 2019;28:e12818.

16. Madsen MT, Huang C, Zangger G, Zwisler ADO, Gögenur I. Sleep disturbances in patients with coronary heart disease: a systematic review. J Clin Sleep Med. 2019;15:489-504.

17. Buysse DJ, Reynolds 3rd, CF, Monk TH, Berman SR, Kupfer DJ. The Pittsburgh Sleep Quality Index: a new instrument for psychiatric practice and research. Psychiatry Res. 1989;28: 193-213.

18. Dong Y, Sharma VK, Chan BP, et al. The Montreal Cognitive Assessment (MoCA) is superior to the Mini-Mental State Examination (MMSE) for the detection of vascular cognitive impairment after acute stroke. J Neurol Sci. 2010;299(1-2):15-8.

19. Ely EW, Inouye SK, Bernard GR, et al. Delirium in mechanically ventilated patients: validity and reliability of the confusion assessment method for the intensive care unit (CAM-ICU). JAMA. 2001;286:2703-10.

20. Sessler CN, Gosnell MS, Grap MJ, et al. The Richmond AgitationSedation Scale: validity and reliability in adult intensive care unit patients. Am J Respir Crit Care Med. 2002;166:1338-44.

21. Peterson JF, Pun BT, Dittus RS, et al. Delirium and its motoric subtypes: a study of 614 critically ill patients. J Am Geriatr Soc. 2006;54:479-84.

22. Silverstein JH, Timberger M, Reich DL, Uysal S. Central nervous system dysfunction after noncardiac surgery and anesthesia in the elderly. Anesthesiology. 2007;106:622-8.

23. Su X, Meng ZT, Wu XH, et al. Dexmedetomidine for prevention of delirium in elderly patients after non-cardiac surgery: a randomised, double-blind, placebo-controlled trial. Lancet. 2016;388: 1893-902.

24. Flink BJ, Rivelli SK, Cox EA, et al. Obstructive sleep apnea and incidence of postoperative delirium after elective knee replacement in the nondemented elderly. Anesthesiology. 2012;116(4):

788-96.

25. Patel J, Baldwin J, Bunting P, Laha S. The effect of a multicomponent multidisciplinary bundle of interventions on sleep and delirium in medical and surgical intensive care patients. Anaesthesia. 2014;69(6):540-9.

26. Fadayomi AB, Ibala R, Bilotta F, Westover MB, Akeju O. A systematic review and meta-analysis examining the impact of sleep disturbance on postoperative delirium. Crit Care Med. 2018;46(12):e1204-12.

27. Faritus SZ, Khazaee-Koohpar M, Ziyaeifard M, Mehrabanian MJ. Oral dexmedetomidine versus midazolam as anesthetic premedication in children undergoing congenital heart surgery. Anesth Pain Med. 2015;5(3):e25032.

28. Song B, Li Y, Teng X, Li X, Yang Y, Zhu J. The effect of intraoperative use of dexmedetomidine during the daytime operation vs the nighttime operation on postoperative sleep quality and pain under general anesthesia. Nat Sci Sleep. 2019;11:207-215.

29. Hwang JH, Chang IS, Park SW, Kwon WK, Hwang JJ. Sole use of dexmedetomidine for sedation and analgesia in patients undergoing endovenous thermal ablation for incompetent saphenous veins. Ann Transl Med. 2019;7(22):638.

30. Järvelä K, Porkkala H, Karlsson S, Martikainen T, Selander T, Bendel S. Postoperative delirium in cardiac surgery patients. J Cardiothorac Vasc Anesth. 2018;32:1597-602.

31. Smulter N, Lingehall HC, Gustafson Y, et al. Disturbances in oxygen balance during cardiopulmonary bypass: a risk factor for postoperative delirium. J Cardiothorac Vasc Anesth. 2018;32: 684-90.

32. Hirsch J, DePalma G, Tsai TT, Sands LP, Leung JM. Impact of intraoperative hypotension and blood pressure fluctuations on early postoperative delirium after non-cardiac surgery. $\mathrm{Br} \mathrm{J}$ Anaesth. 2015;115:418-26.

33. Kang SY, Seo SW, Kim JY. Comprehensive risk factor evaluation of postoperative delirium following major surgery: clinical data warehouse analysis. Neurol Sci. 2019;40:793-800.

34. Raats JW, van Eijsden WA, Crolla RM, Steyerberg EW, van der Laan L. Risk factors and outcomes for postoperative delirium after major surgery in elderly patients. PLoS One. 2015;10:e0136071.

35. Rudolph JL, Jones RN, Rasmussen LS, Silverstein JH, Inouye SK, Marcantonio ER. Independent vascular and cognitive risk factors for postoperative delirium. Am J Med. 2007;120:807-13.

36. Krenk L, Kehlet H. Postoperative obstructive sleep apnea and delirium? Anesthesiology. 2012;117:1392-3.

37. Flink BJ, Rivelli SK, Cox EA, et al. Obstructive sleep apnea and incidence of postoperative delirium after elective knee replacement in the nondemented elderly. Anesthesiology. 2012;116: 788-96.

38. Kim WH, Kim JH, Kim BS, et al. The role of depression in the insomnia of people with subjective memory impairment, mild cognitive impairment, and dementia in a community sample of elderly individuals in South Korea. Int Psychogeriatr. 2017; 29:653-61.

39. Fortier-Brochu E, Morin CM. Cognitive impairment in individuals with insomnia: clinical significance and correlates. Sleep. 2014;37:1787-98.

40. Li Y, Liu H, Weed JG, et al. Deficits in attention performance are associated with insufficiency of slow-wave sleep in insomnia. Sleep Med. 2016;24:124-30.

41. Shen YC, Kung SC, Chang ET, Hong YL, Wang LY. The impact of obesity in cognitive and memory dysfunction in obstructive sleep apnea syndrome. Int J Obes (Lond). 2019;43:355-61.

42. Kung SC, Shen YC, Chang ET, Hong YL, Wang LY. Hypercapnia impaired cognitive and memory functions in obese patients with obstructive sleep apnoea. Sci Rep. 2018;8:17551.

43. Gray JD, Milner TA, McEwen BS. Dynamic plasticity: the role of glucocorticoids, brain-derived neurotrophic factor and other trophic factors. Neuroscience. 2013;239:214-27.

44. Revest JM, Le Roux A, Roullot-Lacarrière V, et al. BDNF-TrkB signaling through Erk1/2 MAPK phosphorylation mediates the enhancement of fear memory induced by glucocorticoids. Mol Psychiatry. 2014;19:1001-9. 
45. Sun CY, Qi SS, Lou XF, et al. Changes of learning, memory and levels of CaMKII, CaM mRNA, CREB mRNA in the hippocampus of chronic multiple-stressed rats. Chin Med J (Engl). 2006; 119:140-7.

46. Polman JA, Hunter RG, Speksnijder N, et al. Glucocorticoids modulate the mTOR pathway in the hippocampus: differential effects depending on stress history. Endocrinology. 2012;153:4317-27.

47. Lal C, Strange C, Bachman D. Neurocognitive impairment in obstructive sleep apnea. Chest. 2012;141:1601-10.

48. Butt M, Dwivedi G, Khair O, Lip GY. Obstructive sleep apnea and cardiovascular disease. Int J Cardiol. 2010;139:7-16.
49. Fullagar HH, Skorski S, Duffield R, Hammes D, Coutts AJ, Meyer T. Sleep and athletic performance: the effects of sleep loss on exercise performance, and physiological and cognitive responses to exercise. Sports Med. 2015;45:161-86.

50. Robinson TN, Wu DS, Pointer LF, Dunn CL, Moss M. Preoperative cognitive dysfunction is related to adverse postoperative outcomes in the elderly. J Am Coll Surg. 2012;215:12-7; discussion 17-8.

51. Hanley JA, McNeil BJ. The meaning and use of the area under a receiver operating characteristic (ROC) curve. Radiology. 1982; 143:2936. 